\title{
A Literature Review on Institutional Environment and Technological Innovation
}

\author{
Zhuoyan Du \\ College of Business Administration, South China University of Technology, Guangzhou, China \\ Email: jessica_29@126.com
}

How to cite this paper: Du, Z.Y. (2018) A Literature Review on Institutional Environment and Technological Innovation. American Journal of Industrial and Business Management, 8, 1941-1950. https://doi.org/10.4236/ajibm.2018.89130

Received: August 8, 2018

Accepted: September 8, 2018

Published: September 11, 2018

Copyright (c) 2018 by author and Scientific Research Publishing Inc. This work is licensed under the Creative Commons Attribution International License (CC BY 4.0).

http://creativecommons.org/licenses/by/4.0/

\begin{abstract}
This article is a literature review on institutional environment and technology innovation. The author discusses the origin and classification of the institutional environment, has a through understanding of the institutional environment, and examines studies about institutional environment and technology innovation from different perspectives to reach some constructive suggestions to better promote technology innovation.
\end{abstract}

\section{Keywords}

Institutional Environment, Technology Innovation, Government Role, Marketization

\section{Introduction}

In recent years, the importance of technology innovation has been repeatedly discussed, and scholars have studied factors influencing the technology innovation in order to find better ways to enhance the technology innovation level. Among all those factors, the enterprises' external environment, especially the institutional environment is a priority research area.

The institutional environment is an important component of the external environment faced by business operations and industrial development, and has a great impact on the strategic behavior and performance of the enterprise. Therefore, the institutional environment and its changes may influence enterprise strategy and their motivation of technology innovation. In order to promote technological innovation, it is necessary to study the relationship between institutional environment and technological innovation.

This article mainly includes three parts. First is the connotation and classification of the institutional environment. Through the discussion of institutional 
theory and institutional environment, we can have comprehensive understanding of the connotation of the institutional environment. Second is the research status of institutional environment and technological innovation, which focuses on the relevant research on the impact of government intervention, marketization, and financial development on technological innovation. Finally, it summarizes the shortcomings of the existing research, and based on the existing research, puts forward suggestions for improving the institutional environment of enterprise technology innovation.

The significance and contribution of this paper is to explore the connotation of the institutional environment more comprehensively, to make up for the neglect of the integrity of the institutional environment, and to propose a new perspective of technological innovation from the micro level.

\section{The Connotation and Classification of the Institutional Environment}

Institutional environment refers to a series of legal systems, government governance, economic and social environment used to establish the basis of production, exchange and distribution. It is the sum of the factors that influence the formal and informal institutions of the region on the economy. Research on the institutional environment derives from the institutional theory. In view of the importance of the institutional environment to business operations, the perspective of institutional theory has become the third largest research perspective in the field of strategic management research after the industry-based view and resource-based view [1]. The institutional environment is the core construct of institutional theory. The core research issue of institutional theory is what influence the institutional environment has on corporate strategy and performance.

With regard to the definition and development of institutional theory, the representative of the new institutional economics, North, pointed out in the book "Institutions, Institutional Changes and Economic Performance": "Institutions are a social game rule, or more standard, they are some artificially designed and shaped constraints on people's interactions." The system contains formal rules and informal rules. According to North (1993), "Formal rules include political (and judicial) rules, economic rules and contracts". Formal rules are created consciously and in formal form. Including the Constitution, the common law, policies and articles of association, and formal contracts, etc., constitute the social rules system, and jointly restrain people's behavior. Informal rules include "behavioral norms, practices, and self-limiting rules of conduct" [2], which are the concepts, habits, and behavioral rules that people have evolved over long-term social activities and social interactions.

North [2] divides the institutional environment into formal and informal institutions, and Scott refines it on this basis. Scott (1995) [3] believes that institutions are composed of Cognitive, Normative, and Regulative dimensions. The regulative dimension is based on the formulation, supervision and enforcement 
of rules. It is the logic of instrumentality and legal sanctions are the source of its legitimacy. The normative dimension defines the objectives and the appropriate means to achieve the goals. Its legitimacy is based on social beliefs and customs. The cognitive dimension comes from the common beliefs and culture of members in the society.

North and Scott's definition of the institutional environment and the distinction between dimensions are the cornerstones of the measurement of institutional environment. Subsequent research has carried out a more detailed division based on the research of North and Scott [4]-[10]. Classical studies tend to emphasize on informal institutions, while formalizing the formal institution to a broader normative dimension. Therefore, in Scott's classification of the institutional environment, the regulative dimension contains more components, which were further subdivided by subsequent studies, for example, Ghemawat (2001) [11] divided the formal institution into two dimensions: management and economic. Berry et al. (2010) [12] divided the formal institution into economic, financial, political, management and demographic dimensions. These divisions are classified according to institutional functions.

Many domestic scholars have also studied the institutional environment. Lin Yifu (1989) [13] divided the external institutional environment into induced institutional changes and compulsory institutional changes, and the influence of induced institutional changes on enterprises is indirect. In the economic field, Cheng Siwei (1998) [14] believes that the government regulates enterprises through direct and indirect means. Direct means include financial supervision, organizational control, etc., and indirect means include macro guidance, economic planning, industrial policy, as well as fiscal and taxation adjustment. Xia Lijun and Fang Zhiqiang (2005) [15] believe that the institutional environment should include dimensions such as market competition, legal level, institutional reform, and government governance. Fan Gang (2011) [16], Xia Lijun and Chen Xinyuan (2007) [17] found that there are significant differences in the institutional environment between regions in China during the economic transition period. The regulatory institution environment faced by Chinese companies is very complicated, so it is necessary to sort out this institutional environment. One aspect is the influence of the government on enterprises. The relationship between the government and enterprises involves many fields. Zhang Jianjun (2005) [18] believes that the government's control over the business behavior of enterprises is mainly reflected in industrial policies, administrative examination and approval, and control of scarce and key resources. Liu Jibing et al. (2015) [19] divided the institutional environment of China into two levels based on the formal and informal institution. He also took China's national conditions into consideration: one is the policy environment representing the formal institutional environment, mainly including the government environment, the level of public finance expenditure, the legal environment, the educational environment, etc.; the other is the market environment representing the standard informal in- 
stitutional environment, mainly including the financial environment, the technical market environment and the fiscal and tax environment.

\section{The Research Status of Institutional Environment and Technological Innovation}

With the development of science and technology, the importance of technological innovation has become more obvious. Innovation can improve the efficiency of factor resource allocation by influencing the structure of factors, and improve the intensity of knowledge-based service factors and human capital accumulation through innovation to effectively realize industrial transformation and upgrading. In addition, the informatization, intelligence and greening brought about by innovation are the main path for the transformation and upgrading of the manufacturing industry. The ability of technological innovation has far surpassed the traditional comparative advantages of resources and labor. The competitive advantage gained through independent innovation will become the core competitiveness, and it will be able to form an industrial competitive advantage and achieve industrial upgrading.

These discussions have all paid attention to the importance of technological innovation, but they are all considered from the overall level of the industry, while the main body of implementing technological innovation is the enterprise. Therefore we should study the problem of technological innovation from the micro level. Enterprises are the main body of technological innovation. Technological innovation must have a corresponding incentive mechanism because of the non-exclusiveness and risk of its achievements. From the perspective of factor cost, the change of production factor price is one of the driving forces of technological innovation of enterprises. Maintaining a monopoly position is also one of the driving forces for technological innovation in enterprises. However, since the market cannot solve the externalities and risk of technological innovation, the nation's incentives for technological innovation of enterprises are an effective supplement to the incentives for technological innovation, which requires a sound institutional environment.

North believes that innovations in corporate systems such as intra-enterprise and inter-enterprise contractual relationships reduce the transaction costs associated with corporate behavior, so the institutional environment may help companies' technological innovation. In reality, there are many institutional obstacles in the process of promoting technological innovation: talent system, scarcity of science and technology management experts, lack of scientific and technological awareness of entrepreneurs; incentive system, lack of effective incentive mechanism for scientific and technological personnel; legal system, the system of protection of technological property rights is not perfect, and there is no corresponding legal protection for the rights and interests of technology owners; the property rights system, the ownership and quantification of state-owned enterprise technology property rights are more difficult. 
Many scholars have carried out theoretical and empirical research on institutional environment and technological innovation. Cao Qige et al. (2014) [20] studied the impact of regional institutional environment on enterprise technology innovation, and found that the development of market intermediary organizations and the development of factor markets have a significant positive impact on technological innovation. Sun Ting et al. (2011) [21] examined the impact of regional financial intermediation development and government intervention on technological innovation of enterprises, and found that there is a significant positive relationship between the development of regional financial intermediation and technological innovation of enterprises. Technological innovation has a significant negative effect. Further research by Sun Ting and Wen Jun (2012) [22] found that in areas with high levels of financial intermediation, the better the bank credit deal with debt of enterprises, the weaker influence of property rights on technological innovation of enterprises; the improvement of the development level of financial intermediaries may promote capital flow to innovative projects with investment value effectively.

$\mathrm{Wu}$ Yonglin et al. (2015) [23] analyzed the impact of institutional environment on the technological innovation dynamics of high-tech enterprises from the aspects of property rights system, financial environment, political environment and investment environment. The study found that a country's property rights system, financial environment, political environment and investment environment have a significant impact on the technological innovation dynamics of local high-tech enterprises, and China's financial environment and legal system still have shortcomings. Therefore technology innovation has received obstacles and lacks enthusiasm. XuHao and Feng Tao (2018) [24] analyzed the influence of administrative, legal and cultural credits in the institutional environment and the interaction between various sub-items on technological innovation. The "tournament" under fiscal decentralization makes local governments tend to implement local protection and promote low-tech, high-investment production projects, thereby curbing technological innovation; the legal and cultural credit sub-environmental deterioration will improve corporate financing difficulties and liquidity risks and other mechanisms to inhibit technological innovation. In contrast, institutional environmental optimization can drive technological innovation by reducing transaction costs.

There are various ways to divide the institutional environment, and the discussion also has its own focus. The most important ones are the impact of government intervention, marketization, and financial development on technological innovation.

\section{Government intervention on technological innovation}

Regarding the impact of government intervention on technological innovation, XieGuangya and Zhang Wei (2002) [25] believe that the innovation system is the government behavior and market behavior, and is a social system. It is the four elements of government policy, enterprise, research institution, and university and industrial structure dynamic system of dependence, change and incen- 
tive. In this system, government policy is the basis of influence, enterprise is the main body, knowledge innovation and communication are the soul, and industrial restructuring is the result. In addition, some scholars believe that the government should strengthen institutional development to promote the operation of the innovation system. Yang Xiaolong and Song Lili (2008) [26] pointed out that while the government is playing its own role, it should identify its own position and determine the focus of development and guide the direction of innovation. Only under the premise of accurate government positioning, and using this as a basis to mobilize all the limited resources so that human and material resources can be efficiently allocated, can we form innovative core competitiveness and better promote innovation. Han Qinghai et al. (2009) [27] believe that local governments should play two functions in the regional innovation system. On the one hand, they must protect the effective operation of the market, promote innovation through market-based innovation activities in the private sector; on the other hand, they should correct the emergence of market failures and ensure the sustainability of innovation activities.

\section{Marketization level and technological innovation}

Regarding the relationship between marketization level and technological innovation, some scholars believe that the basic role of the market in resource allocation should be exerted, and the main role of science and technology in science and technology innovation should be the role of government without intervention or intervention. Bozeman and Sarewitz (2005) [28] specialize in the phenomenon of "government failure" in the formulation and implementation of US science and technology policy. It is found that government-led science and technology policies are prone to monopolization, eroding public interests, suppressing public value expression and shortsighted behavior, and stagnation of interests. It is not conducive to the sharing of resources.

Chinese economist $\mathrm{Wu}$ Jinglian discussed the role of the government in economic development in the book "Developing China's High-tech Industry-Institutions More Than Technology". He pointed out that the government should keep pace with the times and create a country-specific characteristic way, rather than copying or taking extremes. He also pointed out that only when the market is guaranteed to be fair and orderly, the role of the government can be properly played, through both the market-the invisible hand and the government-the invisible hand, can we promote innovation most effectively and create a more prosperous economy.

\section{Financial development and technological innovation}

Regarding the level of financial development and technological innovation, economist Schumpeter's research is the earliest discussion of financial support for independent innovation. His "Economic Development Theory" published in 1912 demonstrates the economic development of interest, monetary credit and other financial variables. The significant impact of independent innovation, Schumpeter's innovation theory expenditure, the essence of economic development lies in the realization of innovation, and the essence of innovation is the 
combination of production factors. The research on domestic financial support technology innovation is roughly divided into foreign financial support independent innovation policy and its enlightenment to China [29] [30]; the concept, framework and model of financial support independent innovation policy design study [31]; theoretical basis of independent innovation financial policy and research on its tool selection [32] [33]; research on China's independent innovation policy from the perspective of fiscal and taxation policy [34] etc.

\section{Summary and Recommendations}

There are two major problems in these studies. One is that when discussing the institutional environment, the definition of the system is limited to industrial policy, or only one aspect is discussed, and the integrity of the institutional environment is neglected. The existing research discusses the relationship between institutions and corporate strategies, competitive advantages, etc., but they fail to explain the differential impact of different institutions on corporate strategic behavior. The other is that in the existing research, the role of the government and its industrial policies has been overemphasized and overvalued, while the role of enterprises and their strategies at the micro level has been neglected. However, the improvement of innovation capability and the development of industry are not entirely policy-making. While emphasizing the improvement of the institutional environment and the proper play of the role of the government, it is also necessary to conduct research on technological innovation in conjunction with the micro-enterprise layer.

The importance of technological innovation for economic development and transformation and upgrading is self-evident. Based on existing literature research, there are some suggestions about improving the institutional environment for technological innovation.

The first is to promote the innovation of enterprise system and promote enterprises to become the main body of technological innovation. On the one hand, enterprises are the main bearers of technological innovation activities. Technological innovation activities are generated from new products and new process ideas, and they are realized through the acquisition and industrialization of new technologies. This is a complete process, which must be realized through the participation of enterprises. On the other hand, it means that enterprises have sufficient autonomy in technological innovation activities. Under the conditions of market economy, enterprises should become a legal entity and a market competition subject that is "self-employed, self-financing, self-development, self-discipline". At the same time, it is necessary to cultivate the enterprise innovation culture. Enterprise innovation is carried out under the background of enterprise-specific innovation culture. Innovation culture is a combination of values, codes of conduct and social environment conducive to innovation activities, and is the basis for stimulating innovation activities.

Second, we need to develop the innovation of the financing system, attract domestic and foreign funds with intellectual property as the core and pay efforts 
to broaden and divert the main channels of financing, in order to alleviate the constraints of the "funding bottleneck", and meet the huge capital needs of technological innovation. A sound corporate system provides an effective incentive mechanism for continuous innovation. The formulation of the property rights system has established the basic framework of income distribution, thus determining the effectiveness of the incentive system, affecting the rationality of the distribution of innovation benefits, and then affecting the whole process of innovation.

Third, to promote the construction of enterprise-oriented innovation services and security systems, in order to promote the efficient and rapid application and continuous innovation of enterprise information and resources, we should concentrate social resources, mobilize social forces, and gradually cultivate and establish the supporting system for enterprise services.

The vitality and efficiency of innovation depend essentially on the institutional environment. A good institutional environment is conducive to the efficient allocation of innovative resources, which is conducive to the formation of a social atmosphere that stimulates innovation, and is conducive to the rapid and wide application of innovation results. Efforts should be made to optimize the innovative resource allocation mechanism. The government and the market have an irreplaceable important role in the allocation of innovative resources. It is necessary to give full play to the guiding role of the government in the allocation of innovative resources, and should also emphasize the fundamental role of the market, in order to construct an institutional environment that stimulates innovation actively.

\section{Conflicts of Interest}

The author declares no conflicts of interest regarding the publication of this paper.

\section{References}

[1] Peng, M., Sun, S., Pinkham, B. and Chen, H. (2009) The Institution-Based View as a Third Leg for a Strategy Tripod. Academy of Management Perspectives, 23, 63-81.

[2] North, D.C. (1993) Institutions and Credible Commitment. Journal of Institutional \& Theoretical Economics, 149, 11-23. https://doi.org/10.5465/amp.2009.43479264

[3] Scott, W.R. (1995) Institutions and Organizations. Sage Publications, Inc., Thousand Oaks.

[4] Zucker, L. (1988) Institutional Patterns and Organizations: Culture and Environment. Balinger, Cambridge, 3-22.

[5] Xu, D., Yigang, P. and Beamish, P.W. (2004) The Effect of Regulative and Normative Distances on MNE Ownership and Expatriate Strategies. Management International Review, 44, 285-307.

[6] Gaur, A.S. and Lu, J.W. (2007) Ownership Strategies and Survival of Foreign Subsidiaries: Impacts of Institutional Distance and Experience. Journal of Management, 33, 84-110. https://doi.org/10.1177/0149206306295203

[7] Pattnaik, C. and Soonkyoo, C. (2007) Do Institutional Quality and Institutional 
Distance Impact Subsidiary Performance? Academy of Management Annual Meeting.

[8] Garud, R., et al. (2007) Institutional Entrepreneurship as Embedded Agency: An Introduction to the Special Issue. Organization Studies, 28, 957-969. https://doi.org/10.1177/0170840607078958

[9] Bae, J.-H. and Salomon, R.M. (2010) Institutional Distance in International Business Research. Advances in International Management. The Past, Present and Future of International Business and Management, 23, 327-349.

[10] Bruton, G.D., et al. (2010) Institutional Theory and Entrepreneurship: Where Are We Now and Where Do We Need to Move in the Future? Entrepreneurship Theory and Practice, 34, 421-440. https://doi.org/10.1111/j.1540-6520.2010.00390.x

[11] Ghemawat, P. (2001) Distance Still Matters: The Hard Reality of Global Expansion. Harvard Business Review, 79, 137-147.

[12] Berry, H., Guile, M.F. and Zhou, N. (2010) An Institutional Approach to Cross-National Distance. Journal of International Business Studies, 41, 1460-1480. https://doi.org/10.1057/jibs.2010.28

[13] Lin, Y.F., Cai, W. and Shen, M.G. (1989) Strategic Choices for China's Economic Reform and Evelopment. Economic Research, No. 3, 28-35.

[14] Cheng, S.W. (1998) The Status Quo and Outlook of Management Science. Journal of Management Science, No. 1, 8-14.

[15] Xia, L.J. and Fang, Q.Q. (2005) The Wealth Effect of the Acquisition of Listed Companies: Based on the Explanation of Signal Theory and Efficiency Theory. China Accounting and Finance Research, No. 2, 1-49.

[16] Fan, G., Wang, X. and Ma, G. (2011) The Contribution of Marketization to China's Economic Growth. Economic Research Journal, No. 2, 4-14.

[17] Xia, L. and Chen, X. (2007) The Endogenous Decision of the Marketization Process, the Reform Strategy of State-Owned Enterprises and the Corporate Governance Structure. Economic Research, No. 7, 82-95.

[18] Zhang, J. and Zhang, Z. (2005) The Political Strategy of Chinese Private Entrepreneurs. Management World, No. 7, 94-105.

[19] Liu, J., Wang, Q. and Ma, H. (2015) The Influence of Institutional Environment on the Innovation Ability of Strategic Emerging Industries. Science and Technology Progress and Countermeasures, 32, 54-61.

[20] Cao, Q., Ren, G. and Luo, Y. (2014) The Impact of Regional Institutional Environment on Enterprise Technology Innovation. Finance \& Economics, No. 1, 71-80.

[21] Sun, T., Wen, J. and Qin, J. (2011) Financial Intermediary Development, Government Intervention and Enterprise Technology Innovation: Empirical Evidence from China's Transitional Economy. Science and Technology Progress and Countermeasures, 28, 75-79.

[22] Sun, T. and Wen, J. (2012) Financial Intermediary Development, Enterprise Heterogeneity and Technological Innovation. Journal of Xí an Jiaotong University (Social Science Edition), 32, 23-28.

[23] $\mathrm{Wu}, \mathrm{Y}$. and Wan, C. (2015) The Influence of Institutional Environment on the Technological Innovation Power of High-Tech Enterprises. Business Economic Research, No. 13, 97-98.

[24] Xu, H. and Feng, T. (2018) Is Institutional Optimization Optimized to Promote Technological Innovation?-An Empirical Analysis Based on the Inter-Provincial Dynamic Space Panel in China. Journal of Finance and Economics, No. 4, 47-61. 
[25] Xie, G. and Zhang, W. (2002) On the Choice of National Innovation System and Its Policy Tools. Journal of Hunan University (Social Science Edition), 16, 52-55.

[26] Yang, X. and Song, L. (2008) A Review of Regional Science and Technology Innovation Capability Evaluation Research. Business Times, No. 21, 105-106.

[27] Han, Q., Wang, H. and Li, S. (2009) On Local Government Behavior in Regional Innovation System. Chinese and Foreign Entrepreneurs, No. 18, 12-13.

[28] Bozeman, B. and Sarewitz, D. (2005) Public Values and Public Failure in US Science Policy. Science \& Public Policy, 32, 119-136. https://doi.org/10.3152/147154305781779588

[29] Zheng, L. (2008) A Comparative Study of Chinese and Foreign Technology Innovation Financial Support Systems. Scientific Management Research, No. 5, 98-101.

[30] Ding, T. and Hu, H. (2009) International Comparison and Path Design of Financial Support for Science and Technology Innovation. Soft Science, No. 3, 50-54.

[31] Gong, Y. (2009) Research on Financial Support System for Technological Innovation. Science and Technology Management Research, No. 8, 397-399.

[32] Gu, S., et al. (2007) Discussion on the Construction of Multi-Level Capital Market Supporting Independent Innovation. China Soft Science, No. 8, 7-13.

[33] Jiang, Y. and Xu, R. (2007) Research on Financial Support System of Independent Innovation Enterprises. Inquiry into Economic Issues, No. 11, 145-149.

[34] Gong, X. (2009) Discussion on the Construction of Financial and Financial Support System for Independent Innovation of Small and Medium-Sized Enterprises. Modern Finance and Economics-Fournal of Tianjin, No. 3, 31-34. 